\title{
Damages with High Consequences: Analysis of Perforations in Surgical Latex Operation Gloves from Orthopedic Surgeries
}

\author{
Andreas Enz ${ }^{1}$, Annett Klinder ${ }^{1}$, Hannah Mittelmeier ${ }^{1}$, Günther Kundt ${ }^{2}$, Wolfram Mittelmeier ${ }^{1}$ and \\ Sarah Zaatreh ${ }^{1}$ \\ ${ }^{1}$ Department of Orthopedics, University Medicine Rostock, Rostock, Germany \\ ${ }^{2}$ Institutes for Biostatistics and Informatics in Medicine and Ageing Research, University of Rostock, Rostock, Germany
}

Received: 06 October 2018; accepted: 14 October 2018

\begin{abstract}
Introduction: To prevent surgical site infections (SSIs) during operation, the use of sterile surgical latex gloves is common. The aim of this study was to examine the damage of the gloves in surgeries with different mechanical stress and the influence on the kind of damages. Gloves were collected during primary arthroplasty, revision arthroplasty (hip and knee), and arthroscopy (shoulder, hip, and knee).

Materials and methods: Surgical latex operation gloves were collected from surgeons after the operation and were tested with watertightness test (ISO EN 455-1:2000).

Results: A total of 1460 surgical gloves were retrieved from 305 elective operations. On average, $15.9 \%$ of the gloves showed postoperative lesions, with the highest incidence occurring in revision arthroplasty with $25 \%$. In primary and revision arthroplasty, the index finger of the dominant hand was most frequently affected $(62.7 \%$ and $58.6 \%$ ); in contrast, gloves from arthroscopies had most lesions on thumb and middle finger (42.9\% each). Tear and perforation size differed from $\leq 1 \mathrm{~mm}$ to $>5 \mathrm{~mm}$, and primary and revision arthroplasty showed bigger damages.

Conclusions: Surgical gloves have a high malfunction, which increases with growing mechanical stress. A high rate of perforation occurred mostly in revision arthroplasty. Breaching the integrity of the gloves, especially by high mechanical loads, could lead to an increased rate of infection.
\end{abstract}

Keywords: latex surgical gloves, damage, perforations, orthopedic surgery, surgical side infection, ISO EN 455-1:2000

\section{Background}

Since Ernst von Bergmann and Ignaz Semmelweis postulated the asepsis in the modern surgery, the use of sterile gloves during operations is one of the main pillars of hygiene [1]. As an impenetrable safety barrier for different body fluids and germs in general, they protect patients and surgical staff $[2,3]$. Although the infection rate, e.g., joint replacement or restoring joint interventions, remained steady in recent years [4], increasing numbers of operations led to a rise in the total number of surgical site infections (SSIs). The prevention of SSIs is one of the major tasks nowadays, and an algorithm of glove use plays a major part (Harnoss 2010). However, this thin layer of latex is not expected to be tested to the highest standard of quality control. The existing ISO EN 455-1:2000 simply tests for impermeability of water and tearproofness, with an acceptable quality level (AQL) of 1.5, while other latex products such as condoms undergo considerably stricter testing for the user's safety (AQL 0.25) $[5,6]$. Mechanical stress such as shear strain, repetitive movements, and sharp surfaces are neglected when testing surgical gloves. The aim of this study was to show whether operations with different levels of mechanical stress have an impact on the type of perforation and hence different risks of contamination. The watertightness test of ISO EN 455 was therefore performed on gloves after primary joint arthroplasty (PA), revision joint

*Author for correspondence: Doberaner Str. 142, 18057 Rostock, Germany; E-mail: AndreasEugen.Enz@med.uni-rostock.de; Tel.: +49 381494 9359; Fax: +49 381494 9308; Trial identification number: A 2016-0112. arthroplasty (RA), and arthroscopic intervention (AY) in order to compare the quantity and quality of glove perforation.

\section{Materials and Methods}

Study Design and Collection of Data. At the Department of Orthopedics of University Medicine Rostock, surgical gloves used during selected types of operations were collected from May 1st, 2016 to December 1st, 2017. These operations included primary hip and knee arthroplasty, hip and knee revision arthroplasty, and hip, knee and shoulder arthroscopy. During the course of the study, 1460 surgical gloves were retrieved from 305 elective operations - 104 primary endoprosthetic, 100 revision arthroplasties, and 101 arthroscopic surgeries. The analysis of damage to surgical gloves was performed within $24 \mathrm{~h}$ after the surgery. The number of used gloves, number of gloves per surgery, type of surgery (knee, hip or shoulder), duration of the surgery, type of surgeon, and use of bone cement were documented, as well as whether bone cement was removed during the revision surgery.

Surgical Gloves. Sterile, powder-free disposable latex gloves for single use (ProtexisTM, Cardinal Health, Dublin, Ohio, USA) were the standard gloves utilized during the different surgeries. At the Orthopedics Department of University Medicine Rostock, the surgical procedure involves using double gloving. One pair of gloves which we refer to as outer gloves is worn over the other. Exchanges of gloves were conducted intraoperatively, when damage to the gloves was observed during surgery. For this changing process, the glove is removed and then turned inside out.

This is an open-access article distributed under the terms of the Creative Commons Attribution-NonCommercial 4.0 International License (https://creativecommons.org/licenses/by-nc/4.0/), which permits unrestricted use, distribution, and reproduction in any medium for non-commercial purposes, provided the original author and source are credited, a link to the CC License is provided, and changes - if any - are indicated. 
Table 1. Statistical analysis of demographic patient data

\begin{tabular}{|c|c|c|c|c|}
\hline Patient data & Patients with primary arthroplasty & Patients with revision arthroplasty & Patients with arthroscopy & $\overline{p \text {-value }}$ \\
\hline Number of recruited patients $[n]$ & 104 & 100 & 101 & \\
\hline Male $[n,(\%)]$ & $49(47.1)$ & $49(49.0)$ & $47(46.5)$ & $0.935^{a}$ \\
\hline Female $[n,(\%)]$ & $55(52.9)$ & $51(51.0)$ & $54(53.5)$ & \\
\hline Age in years $[$ mean $\pm \mathrm{SD}$, (range) $]$ & $68.1 \pm 11.4(20-84)$ & $68.9 \pm 10.4(22-84)$ & $47.6 \pm 16.3(12-82)$ & $<0.0001^{b}$ \\
\hline Body mass index $[$ mean $\pm \mathrm{SD}$, (range) $]$ & $29.9 \pm 5.5(19.2-49.3)$ & $29.2 \pm 5.4(17.6-44.4)$ & $27.9 \pm 4.9(16.8-42.8)$ & $0.024^{b}$ \\
\hline
\end{tabular}

Collection and Integrity Testing of the Gloves. All gloves (outer and inner) were safely kept after a surgery. The samples were gathered in a plastic bag, then sealed and labelled. The patient's name and date of birth, the name of the surgeon, and the date and type of the operation were documented. The examination of tears and micro perforations of the surgical gloves was executed within $24 \mathrm{~h}$ by applying the freedom from holes testing method described in the ISO EN 4551:2000, Medical gloves for single use Part 1: Requirements and testing for freedom from holes, watertightness test (16), as well as described in a previous work from Zaatreh et al. [7].

Thereafter, the dimensions of the tears and perforations were measured using a plastic goniometer (Kirchner \& Wilhelm GmbH \& Co. KG, Asperg, Germany). The damage location was classified in accordance to the finger on which it was identified.

Statistical Analysis. The collected data were analysed with SPSS statistical package version 22 (IBM Corp., New York, USA). Descriptive statistics were computed for continuous and categorical variables. Continuous variables are shown as means and standard deviations (SD). Categorical factors are expressed as frequencies $(n)$ with percentages in brackets.
Testing for differences between the different types of surgery of categorical factors was accomplished by Fischer's exact test (two categories) or by Pearson's chi-squared test (more than two categories). Testing for differences of continuous variables between the different types of surgery was performed by Kruskal-Wallis test. The level of significance was set at 0.05 .

Ethics Statement. Ethical approval to access the patient's data was granted by the Local Ethical Committee of Rostock, Germany (registration number: A2016-0112). Data from the patient's medical files (gender, age, BMI, age, date and type of operation) which were unrelated to the study and obtained as part of standard clinical procedure were collected retrospectively.

\section{Results}

General Patient Data and Surgical Procedure. Demographic data of the 305 participating patients are listed in Table 1. A total of 1460 surgical gloves were collected with 540 gloves derived from 104 primary arthroplasty operations, 669 gloves from 100 revision arthroplasty operations, and 251 gloves from 101 arthroscopy operations.

Table 2. Statistical analysis of surgery data in relation to occurrence of glove damage

\begin{tabular}{|c|c|c|c|c|}
\hline Surgery specific data & Primary arthroplasty & Revision arthroplasty & Arthroscopy & $p$-value \\
\hline Total number of individual gloves collected $[n]$ & 540 & 669 & 251 & 1460 in total \\
\hline $\begin{array}{l}\text { Individual surgical gloves } \\
\text { Undamaged }[n,(\%)] \\
\text { Damaged }[n,(\%)]\end{array}$ & $\begin{array}{c}481(89.1) \\
59(10.9)\end{array}$ & $\begin{array}{l}502(75.0) \\
167(25.0)\end{array}$ & $\begin{array}{c}244(97.2) \\
7(2.8)\end{array}$ & $<0.0001^{a}$ \\
\hline Number of surgical gloves per operation $[$ mean $\pm \mathrm{SD}]$ & $5.2 \pm 2.1$ & $6.7 \pm 3.0$ & $2.5 \pm 0.9$ & $<0.0001^{b}$ \\
\hline Number of damaged surgical gloves per operation $[$ mean $\pm \mathrm{SD}]$ & $0.6 \pm 0.9$ & $1.7 \pm 1.6$ & $0.1 \pm 0.3$ & $<0.0001^{b}$ \\
\hline $\begin{array}{l}\text { Type of joint with intervention } \\
\text { Shoulder }[n,(\%)] \\
\text { Hip }[n,(\%)] \\
\text { Knee }[n,(\%)]\end{array}$ & $\begin{array}{c}- \\
77(74.1) \\
27(25.9)\end{array}$ & $\begin{array}{l}- \\
34(34.0) \\
66(66.0)\end{array}$ & $\begin{aligned} 20 & (19.8) \\
6 & (5.9) \\
75 & (74.3)\end{aligned}$ & $<0.0001^{a}$ \\
\hline $\begin{array}{l}\text { Surgery performed by } \\
\text { Main surgeon }[n,(\%)] \\
\text { Surgeon in training }[n,(\%)]\end{array}$ & $\begin{array}{l}72(69.2) \\
32(30.8)\end{array}$ & $\begin{array}{c}94(94.0) \\
6(6.0)\end{array}$ & $\begin{array}{l}84(86.1) \\
17(13.9)\end{array}$ & $<0.0001^{a}$ \\
\hline $\begin{array}{l}\text { Use of bone cement in operation } \\
\text { Cemented }[\mathrm{n},(\%)] \\
\text { Uncemented }[\mathrm{n},(\%)]\end{array}$ & $\begin{array}{l}73(70.2) \\
31(29.8)\end{array}$ & $\begin{array}{l}52(52.0) \\
48(48.0)\end{array}$ & $\begin{array}{l}- \\
-\end{array}$ & $0.0096^{c}$ \\
\hline $\begin{array}{l}\text { Removal of bone cement in operation } \\
\text { Yes }[n,(\%)] \\
\text { No }[n,(\%)]\end{array}$ & - & $\begin{array}{l}49(49.0) \\
51(51.0)\end{array}$ & $\begin{array}{l}- \\
-\end{array}$ & \\
\hline $\begin{array}{l}\text { Operation time in min [mean } \pm \mathrm{SD} \text {, (range)] } \\
{ }^{a} \text { Chi-square test. } \\
{ }^{b} \text { Kruskal-Wallis test. } \\
{ }^{c} \text { Fischer's exact test. }\end{array}$ & $\begin{array}{c}79.3 \pm 23.3 \\
(28-140)\end{array}$ & $\begin{array}{c}116.8 \pm 48.4 \\
(30-310)\end{array}$ & $\begin{array}{c}40.7 \pm 20.5 \\
(15-112)\end{array}$ & $<0.0001^{b}$ \\
\hline
\end{tabular}


Table 3. Position of glove damage

\begin{tabular}{lccc}
\hline $\begin{array}{l}\text { Position of damage } \\
\text { on the glove }\end{array}$ & $\begin{array}{c}\text { Primary } \\
\text { arthroplasty }\end{array}$ & $\begin{array}{c}\text { Revision } \\
\text { arthroplasty }\end{array}$ & Arthroscopy \\
\cline { 2 - 4 } & {$[n,(\%)]$} & {$[n,(\%)]$} & {$[n,(\%)]$} \\
\hline Thumb & $11(18.6)$ & $32(19.2)$ & $3(42.9)$ \\
Index finger & $37(62.7)$ & $98(58.6)$ & $0(0)$ \\
Middle finger & $8(13.5)$ & $21(12.6)$ & $3(42.9)$ \\
Ring finger & $0(0)$ & $4(2.4)$ & $1(14.2)$ \\
Little finger & $0(0)$ & $0(0)$ & $0(0)$ \\
Palm of the hand & $3(5.1)$ & $12(7.2)$ & $0(0)$ \\
$p$-value (chi-square test) & & & 0.0241 \\
Total & $59(100)$ & $167(100)$ & $7(100)$ \\
\hline
\end{tabular}

Table 2 shows the comparison of the three types of surgeries, namely, primary joint arthroplasty (PA), revision arthroplasty (RA), and arthroscopy (AY), regarding certain surgery dependent factors. There were significant differences in the number of damaged gloves depending on the type of surgery. While after AY nearly all gloves $(97.2 \%)$ were undamaged, this number decreased to $89 \%$ in $\mathrm{PA}$ and was the lowest in RA with $75 \%$. However, considering that $77.0 \%$ of the RA surgeries recorded at least one damaged glove compared to $32.7 \%$ for $\mathrm{PA}$ and $6.9 \%$ in $\mathrm{AY}$, the number of undamaged gloves was still high with $75 \%$. This suggests that a reliable gloving algorithm was in place which accommodates the increased risk of glove damage with increasing operation time (significant positive correlation between number of damaged gloves and operation time, Spearman correlation with $r=$ 0.520 and $p<0.0001)$ and allows changing the gloves in time. Indeed, the highest number of gloves per operation was recorded for RA which also had the longest operation time (Table 2). While the correlation between number of damaged gloves and operation time was highly significant, the correlation factor only indicates a moderate relationship suggesting that further factors such as certain mechanical stresses play a role. The handling of bone cement during surgery was assumed to be such a factor. Surprisingly, neither the removal of bone cement during RA nor the use of bone cement to fix the implant had any effect on the number of damaged gloves. Mann-Whitney U test showed no significant differences for the number of damaged gloves between surgeries with and without cement removal $(p=0.507)$ or between uncemented and cemented implants $(p=0.262)$ (data not shown).

Position and Dimension of the Damage in Surgical Gloves. There was a significant difference in the position of glove damage between the types of surgery (Table 3). This was due to the distribution after AY being significantly different from the distribution of damage on the gloves after PA ( $p=$ 0.0012) and after RA ( $p=0.0065)$, which both showed a similar pattern. In PA and RA surgeries, the index finger was most often affected with $62.7 \%$ and $58.6 \%$, respectively, while in AY, no lesion was found on the index finger. Here, $42.9 \%$ of the damage was positioned at the thumb; in PA and RA, damage of the thumb only accounted for $18.6 \%$ and $19.2 \%$, respectively. In AY, the middle finger showed $42.9 \%$ of the lesions, whereas in PA and in RA, $13.5 \%$ and $12.6 \%$ of the damages occurred on the middle finger. None of the surgeries recorded any damage on the little finger.

The dimensions of the glove damage ranged from $\leq 1 \mathrm{~mm}$ up to more than $5 \mathrm{~mm}$. The size of the lacerations in the gloves varied significantly between PA, RA, and AY (Table 4). The tears in the surgical gloves collected from AY were exclusively $2 \mathrm{~mm}$ and smaller, while gloves retrieved from PA had larger tears with the majority of tears occurring at a macroscopic size of $2 \mathrm{~mm}$ to $3 \mathrm{~mm}$. Interestingly, smaller tears predominated in the gloves collected from RA with more than $75 \%$ of tears being $2 \mathrm{~mm}$ and smaller.
Table 4. Size of tears at the gloves in $\mathrm{mm}$

\begin{tabular}{lccc}
\hline Size of tears $(\mathrm{mm})$ & $\begin{array}{c}\text { Primary } \\
\text { arthroplasty }\end{array}$ & $\begin{array}{c}\text { Revision } \\
\text { arthroplasty }\end{array}$ & Arthroscopy \\
\cline { 2 - 4 } & {$[n,(\%)]$} & {$[n,(\%)]$} & {$[n,(\%)]$} \\
\hline$\leq 1$ & $8(13.6)$ & $76(45.5)$ & $6(85.7)$ \\
2 & $21(35.6)$ & $54(32.3)$ & $1(14.3)$ \\
3 & $15(25.4)$ & $13(7.8)$ & $0(0)$ \\
4 & $11(18.6)$ & $12(7.2)$ & $0(0)$ \\
$\geq 5$ & $4(6.8)$ & $12(7.2)$ & $0(0)$ \\
$p$-value (chi-square test) & & & $<0.0001$ \\
Total & $59(100)$ & $167(100)$ & $7(100)$ \\
\hline
\end{tabular}

\section{Discussion}

There is possibly only a thin layer of latex between sepsis and asepsis and the success of the surgical outcome for the patient. Gloves were examined after surgeries with different levels of mechanical stress, occurring in PA, RA, and AY. In this present study, all gloves were treated equally as double gloving is well establish in practice, and the necessary effort to discern inner and outer gloves was considered not to bring an additional value [8-12]. Altogether, $15.9 \%$ of the gloves reported damages; however, during RA with increased mechanical stress $25 \%$ of the gloves showed lacerations. The increase of damages with the rise in mechanical stress illustrates the loss of the barrier function of the gloves during surgery. It was also shown that with increasing duration of the intervention, the quantity of lesions increased, thus allowing the migration of pathogens to take place. Therefore, regular glove changes are needed [13]. The shorter operation time with standardized glove changes could explain a consistently lower infection rate in primary endoprotheses despite larger holes compared to RA. As more punctures were found in high mechanical stress interventions, the likelihood of more pathogens migrating also increases. This could be one possible reason why RA have elevated rates of infection [4]. As discussed in detail [7], the index finger of the dominant hand was associated with the highest rate of damage in PA and RA, but in AY no lesion on the index finger was found. When damage in AY occurred, the thumb and the middle finger were equally affected, which is related to the operation technique. Groping and orientating with the index finger is not necessary in AY, but for arthroscopic knotting technique thumb and middle finger are often used, which can explain the raised rate of damages at these two fingers $[14,15]$. Otherwise, open rotating instruments like reamers and drills are not needed and arthroscopic instruments like shavers are specially designed and have their rotating end away from the surgeon gloves [16]. The validity of the current norm ISO EN 455-1:2000 with an AQL of 1.5 is not clear as most of the glove manufacturers set up their own, i.e., stricter, quality requirements for their gloves. Still, an effective ISO EN should be developed including better testing systems like power current test methods, which are usual for testing other high safety latex products [5].

\section{Conclusions}

Latex gloves are commonly used in surgeries as a contamination barrier. Mechanical stress weakens and damages the material. This study showed that the position of damages on the glove and the tear size were specific to certain types of surgery. Specialized gloves for certain surgeries may reduce the rate of damage, and in combination with double gloving, fixed changing intervals, and new glove designs, a further reduction of SSI may be achievable. Considering the importance of patient safety additional tests should be established to improve the safety of the gloves. Watertightness test alone may 
not be sufficient, as micro perforation cannot be detected. Therefore, it seems to be necessary to review and update existing test standards for improved safety.

\section{Authors' Contributions}

All authors initiated the trial and achieved analysis of the data. AE, SZ, and AK drafted the manuscript; all authors reviewed and accepted the final version of the manuscript.

\section{Conflict of Interests}

The authors declare that they have no competing interests.

Acknowledgements. The authors thank Mr. Mario Jackzis (Department of Orthopedics, University Medicine Rostock) for engineering the measuring device.

\section{References}

1. Carter KC, Abbott S, Siebach JL. Five documents relating to the final illness and death of Ignaz Semmelweis. Bull Hist Med. 1995;69:255-70.

2. Leitgeb J, Schuster R, Yee BN, Chee PF, Harnoss JC, Starzengruber P, et al. Antibacterial activity of a sterile antimicrobial polyisoprene surgica glove against transient flora following a 2-hours simulated use. BMC Surg. 2015. doi: 10.1186/s12893-015-0058-5.

3. Guo YP, Wong PM, Li Y, Or PL. Is double-gloving really protective? A comparison between the glove perforation rate among perioperative nurses with single and double gloves during surgery. Am J Surg. 2012;204:210-5. doi: 10.1016/j.amjsurg.2011.08.017.

4. Lindeque B, Hartman Z, Noshchenko A, Cruse M. Infection after primary total hip arthroplasty. Orthopedics. 2014;37:257-65. doi:10.3928/ 01477447-20140401-08.
5. DIN EN ISO 4074 - 2017-09 - Beuth.de [Internet]. [cited 4 Jun 2018]. Available from: https://www.beuth.de/de/norm/din-en-iso-4074/263522064.

6. DIN EN 600 - 1996-04 - Beuth.de [Internet]. [cited 4 Jun 2018]. Available from: https://www.beuth.de/de/norm/din-en-600/2755749.

7. Zaatreh S, Enz A, Klinder A, König T, Mittelmeier L, Kundt G, et al. Prospective data collection and analysis of perforations and tears of latex surgical gloves during primary endoprosthetic surgeries. GMS Hyg Infect Control. 2016;11: Doc25. doi: 10.3205/dgkh000285.

8. Guo YP, Wong PM, Li Y, Or PPL. Is double-gloving really protective? A comparison between the glove perforation rate among perioperative nurses with single and double gloves during surgery. Am J Surg. 2012;204:210-5. doi: 10.1016/j.amjsurg.2011.08.017.

9. Ersozlu S, Sahin O, Ozgur AF, Akkaya T, Tuncay C. Glove punctures in major and minor orthopaedic surgery with double gloving. Acta Orthop Belg. 2007;73:760-4

10. Daeschlein G, Kramer A, Arnold A, Ladwig A, Seabrook GR, Edmiston CE. Evaluation of an innovative antimicrobial surgical glove technology to reduce the risk of microbial passage following intraoperative perforation. Am J Infect Control. 2011;39:98-103. doi: 10.1016/j. ajic. 2010.05.026

11. DIN EN 455-1:2001-01 - Beuth.de [Internet]. [cited 8 Oct 2016]. Available from: https://www.beuth.de/de/norm/din-en-455-1/30945341.

12. Laine T, Aarnio P. How often does glove perforation occur in surgery? Comparison between single gloves and a double-gloving system. Am J Surg. 2001;181:564-6.

13. Harnoss J-C, Partecke L-I, Heidecke C-D, Hübner N-O, Kramer A, Assadian $\mathrm{O}$. Concentration of bacteria passing through puncture holes in surgical gloves. Am J Infect Control. 2010;38:154-8. doi: 10.1016/j.ajic.2009.06.013.

14. Giordano V, Koch HA, De JSP, De LM, De RAH, De FS, et al. Is the surgical knot tying technique associated with a risk for unnoticed glove perforation? An experimental study. Patient Saf Surg. 2014;8:26. doi:10.1186/ 1754-9493-8-26.

15. Kaplan KM, Gruson KI, Gorczynksi CT, Strauss EJ, Kummer FJ, Rokito AS. Glove tears during arthroscopic shoulder surgery using solid-core suture. Arthrosc J Arthrosc Relat Surg Off Publ Arthrosc Assoc N Am Int Arthrosc Assoc. 2007;23:51-6. doi: 10.1016/j.arthro.2006.10.012.

16. Goldman AH, Haug E, Owen JR, Wayne JS, Golladay GJ. High Risk of Surgical Glove Perforation From Surgical Rotatory Instruments. Clin Orthop. 2016;474:2513-7. doi: 10.1007/s11999-016-4948-3 